\title{
Therapeutic Effectiveness of Galphimia glauca in Young People with Social Anxiety Disorder: A Pilot Study
}

\author{
Ofelia Romero-Cerecero (iD, Ana Laura Islas-Garduño, \\ Alejandro Zamilpa $\mathbb{D}$, Ma. Dolores Pérez-García, and Jaime Tortoriello \\ Centro de Investigación Biomédica del Sur, Instituto Mexicano del Seguro Social (CIBIS-IMSS), Xochitepec, Morelos, Mexico \\ Correspondence should be addressed to Ofelia Romero-Cerecero; orcerecero@yahoo.com.mx \\ and Jaime Tortoriello; jtortora2@yahoo.es
}

Received 11 May 2018; Revised 24 August 2018; Accepted 13 September 2018; Published 27 September 2018

Academic Editor: Marco Leonti

Copyright (c) 2018 Ofelia Romero-Cerecero et al. This is an open access article distributed under the Creative Commons Attribution License, which permits unrestricted use, distribution, and reproduction in any medium, provided the original work is properly cited.

Social anxiety is one of the most common disorders found in the population attending the first level of health care. Galphimia glauca has been used for many years in Mexican traditional medicine to treat "nervous disorders". A standardized extract of this species has been evaluated in clinical studies that have proven its efficacy and safety in patients with generalized anxiety disorder. In this work, a double-blind clinical trial was carried out, using sertraline as a control. Patients from both sexes (18 to 35 years old) with moderate or severe social anxiety were included. Experimental group was treated daily (orally), for 10 weeks, with an extract from G. glauca containing $0.374 \mathrm{mg} / \mathrm{dose}$ of Galphimine-B (G-B, active compound). Patients in the control group were given sertraline $(50 \mathrm{mg})$ in the same conditions. All patients were evaluated every two weeks. Another assessment was done one month after the end of the administration period. A total of 34 patients was included, 17 in each group. Women were predominant, and the mean age was $25 \pm 4.7$ years. In patients who received the G. glauca standardized extract, a significant reduction in anxiety was observed, with a value (in the Brief Social Phobia Scale) of $41.1 \pm 10.3$ points at the start and $11.2 \pm 5.6$ points at the end of treatment, while patients treated with sertraline had a value of $37.7 \pm 7.3$ points at the beginning and $11.1 \pm 5.2$ points at the end. No significant difference was observed between the treated groups. In a similar way, the health scale showed a gradual and continuous improvement in each of the five evaluations. In conclusion, the 10-week oral administration of G. glauca standardized extract showed efficacy and safety in patients with social anxiety disorder, without showing a significant difference from patients treated with sertraline.

\section{Introduction}

Disability caused by mental disorders has become more important than other produced by chronic diseases due to the fact that it appears in younger people [1]. Anxiety disorders are the most frequent mental diseases present in the population. A study reported that in Latin America and the Caribbean, more than half of the patients with some mental disease had had some type of anxiety [2]. Within the classification of anxiety disorders, social anxiety is described as one of those which presents itself most frequently in the young population, but it is also placed within the category of anxiety disorders in adults with onset in childhood [3].

Epidemiological studies have shown that social anxiety is one of the most common disorders found in the general population attending the first level of health care [4-7]. Interest in social anxiety has increased in the last years, and its high prevalence has been clearly identified $[8,9]$. The personality traits that are associated with social anxiety are as follows: fear of rejection, low self-esteem, feelings of inferiority, difficulty in self-affirmation, and great susceptibility to criticism and negative opinions/lack of appreciation of others [10].

The medicinal plant species Galphimia glauca, a native species of Mexico [11], is commonly known as "calderona amarilla" (Mexico) or "thryallis" (USA) and has been used in Mexican traditional medicine, for many years, to treat central nervous system disorders, specially as a nervous tranquilizer [12]. The scientific study of this plant began more than two decades ago, through different neuropharmacology models, where it became evident that the methanol extract of $G$. glauca has an inhibitory effect on the central nervous system (CNS) [13]. Through a biodirected chemical separation, a 
new nor-seco-triterpenoid was discovered, which was called Galphimine-B (G-B) [14]. The new compound was subjected to different pharmacological evaluations, through which it was discovered that the G-B possesses a novel action. The compound produced modifications in the neuron discharge rate of the ventral tegmental area (VTA) $[15,16]$. The effects produced by G-B are selective for the dopaminergic neurons which, besides not interacting with the GABAergic system, are capable of blocking the effects produced by glutamate on the NMDA ionotropic receptors [17]. A phytopharmaceuticals, elaborated with G. glauca extract and standardized in its G-B content, was administered to patients who had generalized anxiety disorder. It had a substantial anxiolytic effect, very similar to that produced by lorazepam (which was used as the control treatment), but was better tolerated, since many of the patients treated with lorazepam had to withdraw from the study due to the side effects [18]. In the present work, phytopharmaceuticals prepared with a standardized $G$. glauca extract were evaluated in a double-blind clinical trial, using sertraline as a control, in young people suffering from social anxiety.

\section{Material and Methods}

2.1. Plant Material. The plant material used in the study, aerial parts of Galphimia glauca Cav., of the Malpighiaceae family, was obtained from a controlled crop in the state of Morelos, Mexico. Identification was done by M.S. Abigail Aguilar Contreras, and a voucher sample was deposited at the IMSSM Herbarium with registration number: IMSSM-11061.

2.2. Preparation of Plant Extract. The plant's aerial parts $(10$ $\mathrm{kg}$ ) were selected and subjected to a drying procedure at room temperature and protected from light. Once dry, the material was ground with $5 \mathrm{HP}$ electric equipment to obtain $<5 \mathrm{~mm}$ particles. The dry and ground material was degreased with hexane and then extracted with a $60 \%$ ethanol/water mixture at $50^{\circ} \mathrm{C}$, for two hours. The solvent was eliminated from the extract totally, through a reduced pressure distillation process. The dry product was extracted in ethyl acetate and partitioned with water. The organic phase was concentrated once more and dried in high-vacuum. The final yield of the extract was $23.6 \%$. The obtained extract was analyzed by HPLC in order to identify the G-B content. This information was needed to prepare the pharmaceutical formulation.

\subsection{High-Performance Liquid Chromatograph Analysis} (HPLC). The dry extract of Galphimia glauca was analyzed in a modular HPLC system (Waters) constituted by a 2695 separation model (Alliance; Waters) and a 2996 photodiode detector (Waters). The equipment was controlled with a data capture computer software program (Empower pro; Waters). The chromatographic method was developed in a reverse-phase column (Alttima, RP- 18, $3 \mu \mathrm{m}, 4.6$ $\times 70 \mathrm{~mm}$; Merck). The mobile phase comprised a 35:65 acetonitrile/water isocratic system eluted at a $1.7 \mathrm{~mL} / \mathrm{min}$ flow with a 21 min run time. The fingerprints were obtained at a $220 \mathrm{~nm}$ wavelength. For the calibration curve, four

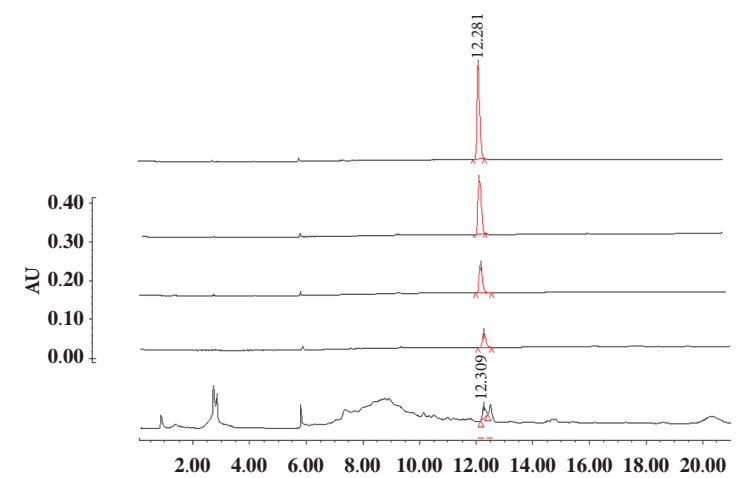

FIgURE 1: Chromatographic analysis of ascendant concentrations of galphimine-B (G-B, 25, 50100 and $200 \mathrm{mg} / \mathrm{mL}$ ) and fingerprint of anxiolytic treatment from G. glauca.

ascendant concentrations of G-B which were previously isolated from Galphimia glauca extract were injected in the same chromatographic method (Figure 3). This methodology allowed us to discover that the G. glauca extract contained 53 $\mathrm{mg} / \mathrm{g}$ of G-B (Figure 1).

2.4. Preparation of Treatments. The formulation of the experimental treatment was done using the standardized G. glauca extract. For each dose, the amount of dry extract used was needed to reach a G-B concentration of $0.374 \mathrm{mg}$. The product was added and mixed with the vehicle in a uniform manner and then packed into hard gelatin capsules.

Sertraline was used as a control treatment, and it was purchased from a pharmaceutical supplier. In each dose, $50 \mathrm{mg}$ of sertraline was used and this was added to and uniformly mixed with the vehicle. The product was packed in hard gelatin capsules that were identical to the ones in the experimental treatment.

For the secondary packaging of the capsules, experimental as well as control, 10 unit aluminum blisters were used. Both treatments were labeled to identify the research project. The containers were packed in individual cardboard boxes, also labeled with the project data and controlled through reference numbers.

2.5. Clinical Study. A clinical, prospective, double-blind, and randomized study was carried out, using sertraline as a control. The study population was formed by patients attending the Regional General Hospital (Hospital General Regional) of the Mexican Institute of Social Security (IMSS) in the state of Morelos, Mexico. Patients were assigned through a table of random numbers to one of two treatment groups. The experimental group received treatment with a standardized G. glauca extract and the control group was administered with sertraline.

Women and men between ages 18 and 35 were included, who had a diagnosis of moderate or severe social anxiety. The measurement instrument used for diagnosis was the Brief Social Phobia Scale (BSPS) [19], which contains 17 items, with five response options that each provides a value from 0 to 4. The sum of the values gives us the total points presented 
by each of the participants. When the questionnaire that was applied to the candidate showed a total value of 31 points or more (significant social anxiety), the patient was considered to be a candidate to be admitted in the study.

Once a candidate had been identified to be included in the study, a physician (who had been trained in the development of clinical projects) was in charge of performing a medical history and a medical examination in order to corroborate the diagnosis of social anxiety and the person's general state of health. Other criteria taken into account to include a candidate in the project were as follows: (a) not having had treatment for their ailment, at least for a month prior to their admittance in the project and (b) in the case of women in reproductive age, not being pregnant or breast-feeding. To formally enter the study, all patients had to sign an informed consent letter. It was also necessary to carry out clinical laboratory studies, which included the following: hematic biometry (HB), general urine test, glutamic pyruvic transaminase, glutamic oxaloacetic transaminase, urea, creatinine, and fasting blood glucose.

In the study, no patients were included who had other mental disorders, or with a history of alcoholism, smoking or drug addiction, those living alone, who took drugs for insomnia, or MAO inhibitors, patients with epilepsy, those handling dangerous machinery or who have to drive a motor vehicle for a long time.

Patients included in the experimental group were treated daily (orally), for 10 weeks, with capsules containing the G. glauca extract standardized in its G-B content ( 0.374 $\mathrm{mg} /$ dose). While the control group received capsules with sertraline $(50 \mathrm{mg}$ ) during the same period of administration.

The control and experimental treatments were administered every 24 hours, during the first week and after that, twice a day, until completing ten weeks of administration. During the last two weeks, the treatments were gradually suspended.

Patients were asked to return five times (during the administration period) in order to evaluate their state of health, the evolution of the disease, and adherence to the treatment and its tolerability. During each visit, a health scale assessment instrument was applied to the patients, as well as a Clinical Global Impression scale [20]; the physician also applied this scale. In all evaluations, questions were asked about the presence of side effects, their number, and severity. At the time they joined the study and at the end of the treatment, the BSPS was applied.

At the end of the administration of the treatments, a clinical efficacy evaluation was performed, of patients treated with the phytopharmaceuticals prepared with G. glauca (experimental group), as well as of those who were treated with sertraline (control group). Clinical efficacy was considered to be present when the patient moved to a stage of less severity or to the total remission of symptoms. The following variables were also evaluated: (1) adherence to treatment: this variable was considered when the percentage of consumption of the treatments was equal to or greater than $75 \%$; (2) therapeutic tolerability: this variable was considered to be the absence of severe side effects generated by the treatment, which could justify its discontinuation, (3) therapeutic success: this was considered when there was clinical efficacy and therapeutic tolerability, (4) therapeutic failure: this was considered when there was a lack of clinical efficacy and/or an absence of therapeutic tolerability.

All patients were received by the physician one month later, to evaluate the presence or absence of social anxiety symptoms.

2.6. Ethical Aspects. The research Project was submitted to and approved by the National Committee for Scientific Research and the National Ethics Committee of the Mexican Institute of Social Security and received registration number R-2014-785-092 from the Health Research Direction. The study was carried out according to the guidelines of the Helsinki and Tokyo Declarations for humans. Each patient included in the study received detailed information on the clinical procedure and signed a letter of informed consent.

2.7. Statistical Analysis. The results of the study are reported as percentages and frequencies and were analyzed through descriptive statistics, using the STATA 14 program. The $\mathrm{X}^{2}$ test was used for the analysis of differences in proportions and the ANOVA test for the difference in means. Values of $p$ that were under 0.05 were used to define significant differences among the groups.

\section{Results}

3.1. Clinical Trial. A total of 34 patients were admitted to the study, of which 17 were included in each treatment group (experimental and control). Of the total number of patients in the study, 3 dropped out of the experimental group and 2 of the control group. The remaining 14 and 15 patients, respectively, continued with the treatment until the end. The statistical analysis of results was done by "intention to treat analysis" (ITT). The initial statistical analysis was applied to all patients, and this included the Brief Social Phobia Scale, and medical history. Those who continued until the end, were applied the follow-up scales: health scale assessment instrument, the Clinical Global Impression Scale and the final BSPS.

Of the total sample, 7 (20.05\%) were men and 27 (79.41\%) were women. The mean age was $25 \pm 4.8$ years. Three patients from the experimental group and two from the control group did not conclude the period of administration. In the experimental group, where patients were treated with the standardized G. glauca extract, two patients abandoned the study for personal reasons; among the patients treated with sertraline, there was one who dropped out, in this case due to a change in residence. Tolerability was similar in both study groups; one patient from each group had to suspend treatment due to side effects. At the end of the treatment, $82.3 \%$ (14) of patients remained in the experimental group and $88.2 \%$ (15) in the control group.

Table 1 shows the personal background and other variables related to the disease in patients included in the study. Although no significant differences are seen between the treatment groups, it is important to note that $35.2 \%$ and 
TABLE 1: Personal background and variables related to the disease, in patients with social anxiety who were included in the group treated with a standardized extract of Galphimia glauca (experimental group) and in the group treated with sertraline (control group).

\begin{tabular}{|c|c|c|c|}
\hline Variable & $\begin{array}{c}\text { Galphimia glauca } \\
\mathrm{n}=17 \\
\% \text { (frequency) }\end{array}$ & $\begin{array}{c}\text { Sertraline } \\
n=17 \\
\% \text { (frequency) }\end{array}$ & $\begin{array}{c}p \\
\mathrm{X}^{2}\end{array}$ \\
\hline \multicolumn{4}{|l|}{ Schooling } \\
\hline Middle School & $23.5(4)$ & $5.8(1)$ & \\
\hline High School & $41.1(7)$ & $57.8(11)$ & 0.24 \\
\hline University & $35.2(6)$ & $29.4(5)$ & \\
\hline \multicolumn{4}{|l|}{ Marital status } \\
\hline Single & $58.8(10)$ & $58.8(10)$ & \\
\hline Married & $31.5(6)$ & $29.4(5)$ & 0.78 \\
\hline Common law marriage & $5.2(1)$ & $5.2(1)$ & \\
\hline Divorced & $0(0)$ & $5.2(1)$ & \\
\hline \multicolumn{4}{|l|}{ Presently studies } \\
\hline Yes & $35.2(6)$ & $29.4(5)$ & 0.71 \\
\hline No & 68.7(11) & $70.5(12)$ & \\
\hline \multicolumn{4}{|l|}{ Working } \\
\hline Yes & $47.0(8)$ & $52.9(9)$ & 0.73 \\
\hline No & $52.9(9)$ & $47.0(8)$ & \\
\hline \multicolumn{4}{|l|}{ Likes to have friends } \\
\hline Yes & $82.3(14)$ & $58.8(10)$ & 0.13 \\
\hline No & $17.6(4)$ & $41.1(7)$ & \\
\hline \multicolumn{4}{|c|}{ Feels accepted by his/her group of friends } \\
\hline Yes & $70.5(12)$ & $76.4(13)$ & 0.69 \\
\hline No & 29.4(5) & $23.5(4)$ & \\
\hline \multicolumn{4}{|c|}{ Likes to live only with relatives } \\
\hline Yes & $58.8(10)$ & $70.5(12)$ & 0.47 \\
\hline No & $41.1(7)$ & $29.4(5)$ & \\
\hline \multicolumn{4}{|l|}{ Prefers solitude } \\
\hline Yes & $82.3(14)$ & $94.1(16)$ & 0.62 \\
\hline No & $17.6(3)$ & $5.8(1)$ & \\
\hline
\end{tabular}

No significant difference was found between the two groups.

$29.4 \%$ of patients in the experimental and control groups, respectively, were students, while $52.9 \%$ and $47.0 \%$, in the same order as above, were not working. Most of the patients, $82.3 \%$ of the experimental group and $94.1 \%$ of the control group, manifested a preference for solitude.

3.2. Measuring Scales. Using the BSPS, under basal conditions, the patients included in the study showed a maximum anxiety level of 60 points in the experimental group and 51 points in the control group. The mean per study group was $41.1 \pm 10.3$ points for the experimental group and $37.7 \pm 7.3$ points in the control group. The statistical analysis showed no evidence significant differences between the groups $(p=$ 0.43 ). At the end of the administration period (10 weeks), the symptomatology diminished with respect to the baseline evaluation by $73.2 \%$ in the patients of the experimental group (who were treated with the standardized extract of $G$. glauca) and, $72.2 \%$ in the patients that received sertraline. As may be seen in Figure 2, we were able to determine that in patients in the experimental group, after ten weeks of treatment, anxiety was significantly reduced to $11.2 \pm 5.6$ points, while, in patients of the control group, it decreased to $11.1 \pm 5.2$ points. The analysis of results did not show statistically significant differences between both groups. In a similar manner, the analysis by means of the health scale shows a gradual improvement, consistent and continuous, in each one of the five appointments attended by the patients. It is important to note that the improvement in patients was observed since the second week of treatment (first medical visit after starting administration) (Figure 3).

The Clinical Global Impression Scale for improvement, answered by both the patients and the physician, showed a continuous tendency towards improvement, throughout the weeks of treatment. Results are shown in Table 2.

3.3. Output Variables. $82.3 \%$ of the experimental group and $88.2 \%$ of the control group concluded the ten weeks of administration of treatments; of these, $14.2 \%$ (2) of patients in the experimental group and $6.6 \%$ (1) of patients in the control group achieved a total absence of symptoms related to the 
TABLE 2: Effect produced by the administration of a standardized extract of G. glauca (experimental group) or sertraline (control group) in patients with a diagnosis of social anxiety, evaluated at two, four, six, eight and ten weeks, using the "Patient's Global Impression Scale for Improvement" and the "Physician's Global Impression Scale for Improvement".

\begin{tabular}{|c|c|c|c|c|c|c|}
\hline \multirow[b]{2}{*}{ Variable } & \multicolumn{3}{|c|}{ Patient's global impression scale for improvement } & \multicolumn{3}{|c|}{ Physician's global impression scale for improvement } \\
\hline & $\begin{array}{c}\text { G. glauca } \\
\% \text { (frequency) }\end{array}$ & $\begin{array}{c}\text { Sertraline } \\
\% \text { (frequency) }\end{array}$ & $p$ & $\begin{array}{c}\text { G. glauca } \\
\% \text { (frequency) }\end{array}$ & $\begin{array}{c}\text { Sertraline } \\
\% \text { (frequency) }\end{array}$ & $p$ \\
\hline \multicolumn{7}{|l|}{ Two weeks } \\
\hline Much better & $17.6(3)$ & $29.4(5)$ & & $52.9(9)$ & $70.5(12)$ & 0.46 \\
\hline Better & $52.9(9)$ & $47.0(8)$ & 0.30 & $29.4(5)$ & $29.4(5)$ & \\
\hline Without changes & $29.4(5)$ & $23.5(4)$ & & $17.6(3)$ & $0(0)$ & \\
\hline \multicolumn{7}{|l|}{ Four weeks } \\
\hline Much better & $50(7)$ & $60(9)$ & & $78.6(11)$ & $93.3(14)$ & 0.44 \\
\hline Better & $21.4(3)$ & $33.3(5)$ & 0.14 & $7.1(1)$ & $6.6(1)$ & \\
\hline Without changes & $28.5(4)$ & $6.6(1)$ & & $14.2(2)$ & $0(0)$ & \\
\hline \multicolumn{7}{|l|}{ Six weeks } \\
\hline Much better & $71.4(10)$ & $66.6(10)$ & & $100(14)$ & $86.6(13)$ & 0.63 \\
\hline Better & $28.5(4)$ & $33.3(5)$ & 0.62 & $0(0)$ & $13.3(2)$ & \\
\hline Without changes & $0(0)$ & $0(0)$ & & $0(0)$ & $0(0)$ & \\
\hline \multicolumn{7}{|l|}{ Eight weeks } \\
\hline Asymptomatic & $7.1(1)$ & $0(0)$ & & $7.1(1)$ & $0(0)$ & \\
\hline Much better & 78.5 (11) & $80(12)$ & & $92.8(13)$ & $86.6(13)$ & 0.51 \\
\hline Better & $14.2(2)$ & $20(3)$ & 0.65 & $0(0)$ & $13.3(2)$ & \\
\hline \multicolumn{7}{|l|}{ Ten weeks } \\
\hline Asymptomatic & $14.2(2)$ & $13.3(2)$ & 0.18 & $14.2(2)$ & $6.6(1)$ & 0.18 \\
\hline Much better & $85.7(12)$ & $86.6(13)$ & & $85.7(12)$ & $93.3(14)$ & \\
\hline
\end{tabular}

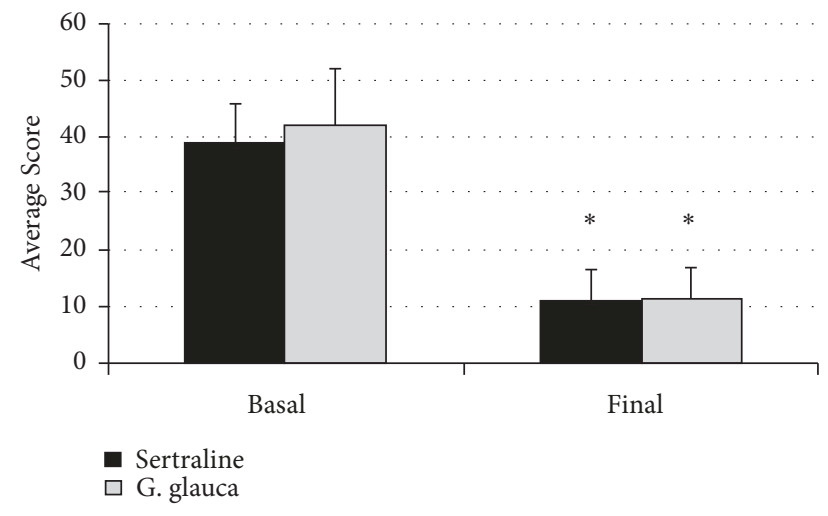

FIGURE 2: Effect produced by the oral administration for ten weeks of the standardized extract of G. glauca (experimental group) or sertraline (control group) on patients with a diagnosis of social anxiety, evaluated by the BSPS scale. $*=p<0.05$ when compared to the basal condition. The statistical analysis showed no difference between the treatment groups $(p>0.05)$.

disease, at the end of treatment administration. The rest of the patients went on to a less severe stage, $85.7 \%$ and $93.3 \%$ in the experimental and control groups, respectively, with no evidence of a statistically significant difference between the groups $(p=0.54)$.

On average, patients in the experimental group perceived improvement in their symptoms at $15 \pm 6.65$ days of treatment, while the patients in the control group perceived improvement at $13 \pm 7.16$ days $(p=0.35)$.

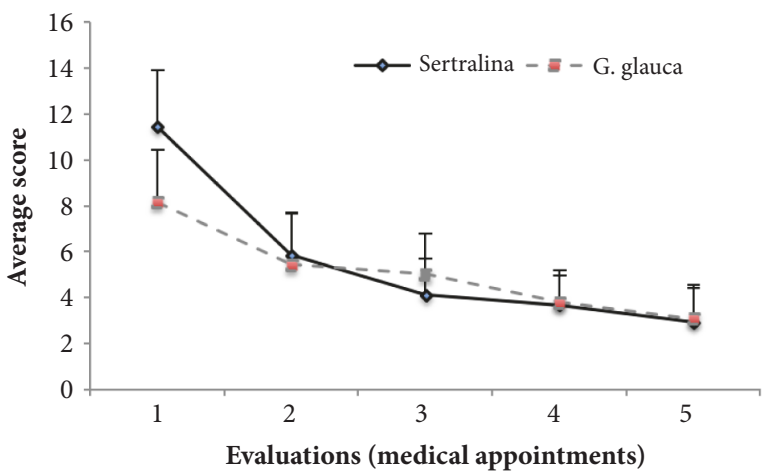

FIGURE 3: Effect produced by the oral administration for ten weeks, of the standardized extract of G. glauca (experimental group) or sertraline (control group) in patients with a diagnosis of social anxiety, evaluated through the health scale. The statistical analysis showed no difference between the treated groups ( $\mathrm{p}>0.05)$.

Adherence to the treatment was considered to be present when the patient consumed $75 \%$ or more of the treatment. Thus, the analysis showed that adherence to the treatment among patients who concluded the study was of $100 \%$ in both groups of treatment.

In general, the total number of patients concluding the ten weeks of treatment (29 patients) stated feeling satisfied with the response of their symptoms after treatment administration. At the end of the treatment, there was $92.8 \%$ therapeutic success in the experimental group and $93.3 \%(p=0.54)$ in the control group. One patient from each group $(7.1 \%$ of 
the experimental group and $6.6 \%$ of the control group) was identified as a therapeutic failure ( $p=0.83)$.

It is important to point out that, during the withdrawal scheme (last two weeks of administration), $100 \%$ of participants who reached the end of the study, in the experimental group as well as in the control group, there was no exacerbation of the clinical profile, nor any added symptoms.

One month after conclusion of the treatment, $86.6 \%$ (13) of patients in the control group and 78.5\% (11) of those in the experimental group went for a follow-up consultation. Of these, $54.5 \%$ (6) of the experimental group and $46.1 \%$ (6) of the control group did not show any symptoms that were compatible with the clinical profile of social anxiety $(p$ $=0.68$ ).

\section{Discussion}

According to the Reports of the Diagnostic and Statistical Manual of Mental Disorders-IV (DSM-IV), social anxiety is the most frequent mental disease that is found in the category of anxiety disorders in adults, with onset in childhood [3]. The results of the present study show that $76.4 \%$ (13) of patients included in the group treated with G. glauca, had had the symptoms since childhood or adolescence. The results were similar in patients treated with sertraline; in this case, the same condition was found in $88.2 \%$ (15) of participants.

Interpersonal relationships are a very important factor in people's behavior and are considered to be greatly needed for survival. These relations can be affected in some people because of the presence of social fear, which can go from inhibiting certain activities such as public speaking, facing authority figures or, in extreme cases, not initiating a new relationship $[19,20]$. It is important to point out the presence of these parameters in the patients included in this study and its evolution after the treatments administration. With this purpose, a questionnaire was used to which patients could respond: absent, scarce, manageable, and unmanageable. Before starting treatment, and on the "fear that patients feel to an authority figure", in both treatment groups the "manageable" response predominated, with $52.9 \%$ and $41.2 \%$ in the experimental and control group, respectively. After 10 weeks of treatment, the response was "absent" in 58.3\% and $63.6 \%$, in the same order. When asked about "Avoids public speaking" in both groups, before starting treatment, the most frequent response was "unmanageable" with 58.8\%. At the end of the treatment, in the experimental group the response was "scarce" in $50 \%$ and absent in $35.7 \%$ of the patients; while in the control group the answer was "scarce" in $66.6 \%$ and "manageable" in $20 \%$. Regarding the item "Fear of being with unknown people", at the basal moment the "manageable" intensity predominated, with $52.9 \%$ in both groups. At the end of the treatment administration, the most frequent response was "scarce", with $76.9 \%$ and $60 \%$ in the experimental and control group, respectively.

Among the patients who were administered G. glauca, the difficulty in socializing was evident, since most of them, $89.4 \%$, said that going to parties or social gatherings was disagreeable to them; the same was stated by those who were treated with sertraline, $98.9 \%(p=0.41)$.
This disease becomes specially important in adolescents due to the possible consequences that social anxiety might generate, such as: (1) low academic performance, which might lead them to drop-out of school, (2) the development of other anxiety disorders or mood problems, (3) the onset of alcohol consumption or of other toxic substances [21-23].

The population included in the study was made up by young patients, most of whom were no longer in school. Of those who were still studying, we discovered that only $50 \%$ from the experimental group, enjoyed participating in classes. In the case of the group treated with sertraline, no participants answered this question affirmatively. In the same way, $100 \%$ of the patients included in the experimental group found exams to be very stressful, a number not very different from that found in the control group (83.5\%). Another figure related to this analysis was that in $100 \%$ of the participants included in both study groups, their grades did not correspond to the effort invested in their courses.

The effectiveness of sertraline has been evaluated in multiple clinical studies related to generalized anxiety or social anxiety. Time of administration has been between 10 and 24 weeks. Evaluation of evolution, using different scales has detected a response to treatment that goes from 30 to $80 \%$. Clinical studies have found that symptoms such as fear, avoidance, restlessness, blushing, and palpitations decrease significantly with sertraline administration $[24,25]$.

Besides the pharmaceutical drugs used to treat anxiety problems, since ancient times, vegetal species with medicinal properties have been used as alternative treatments. Today, there has been considerable progress in the study of these species, but generally the research work involves only preclinical evaluations. For these products to be better appreciated, we need to progress in the development of medicinal prototypes through pharmaceutical formulations with scientific support, which include clinical investigations oriented towards the evaluation of their efficacy, tolerability and safety [26].

There has been continuous progress in the study of the $G$. glauca species. Basic studies in its chemistry and pharmacology have allowed for the isolation and identification of new compounds called galphimines. These compounds have also been found to possess novel mechanisms of action, specificity of action on regions of the central nervous system and on dopaminergic neurons. Also, recent studies have reported the pharmacokinetics of the G. glauca active compounds [27-29]. Prior clinical studies have provided evidence of anxiolytic efficacy similar to that produced by Lorazepam, one of the most widely used benzodiazepines, but with greater tolerability [30]. These findings have placed the G. glauca species in a relevant position within the group of species having clinical efficacy in patients with mental disorders [31]. It has been shown that galphimine-B (active compound from G. glauca) possesses a selective pharmacological action in regions of the CNS, such as VTA, while it also has the ability to inhibit the frequency of discharge of dopaminergic neurons. More specifically, it has the ability to block the effect produced by glutamate on dopaminergic neurons. The results obtained in this study agree with previous reports in which it has been shown that psychostimulants such as amphetamine 
increase the release of dopamine in VTA. This effect of dopamine, specially that generated by the discontinuation of amphetamine, affects social behavior and generates anxiety [32]. Other reports have suggested that dopamine is involved in the etiology and expression of anxiety. An assertion that is further reinforced, by the fact that nonbenzodiazepine drugs, such as dopamine antagonists, exerts clinical efficacy in patients with anxiety [33]. These data are closer to the knowledge of a probable action mechanism of G-B. It is important to highlight that the individual dose (of the active compound G-B) used in the case of the experimental treatment was considerably lower than that used for the control. Even considering the total amount of the extract included in each capsule, the dose of the experimental treatment was lower $(7 \mathrm{mg})$. This means that the amount needed to produce the same effect was lower, which could mean higher pharmacological potency and, consequently, lower amount of drug administration.

In this study we were able to see that the symptoms related to anxiety, which were explored with the BSPS scale, decreased considerably after two weeks of treatment with a phytopharmaceutical prepared with a standardized extract of G. glauca. For example, (1) At the beginning of the study, $100 \%$ of the patients included in this group had fears, which by the end of the study decreased to $53.2 \%$; (2) blushing was present at the initial moment in $84.2 \%$ of participants, and at the end it was present in $36.8 \%$; (3) palpitations were present in $78.9 \%$ of patients at the beginning, and went down to $26.3 \%$ at the end; (4) Normal social activities limitations were reduced from 60 to $20 \%$. It is important to take into consideration that in this study (avoiding living patients without medical treatment) a placebo group was not included; this situation does not allow a comparative analysis to identify a possible placebo effect.

\section{Conclusion}

The oral administration of a Galphimia glauca extract, standardized in its G-B content, showed efficacy and safety in patients with social anxiety disorders, without showing significant differences when compared to patients treated with sertraline.

\section{Abbreviations}

G-B: Galphimine-B

BEFS: Brief scale for social anxiety

CNS: Central Nervous System

VTA: Tegmental ventral area

IMSSM: Herbarium of the Mexican Institute of Social Security

HPLC: High performance liquid chromatography

HB: $\quad$ Hematic biometry

IMAO: Inhibitors of monoamine oxidase.

\section{Data Availability}

The data used to support the findings of this study are available from the corresponding author upon request.

\section{Conflicts of Interest}

The authors have declared that there are no conflicts of interest

\section{Acknowledgments}

The authors are grateful for the support received to carry out this project. This work received support from the Mexican Institute of Social Security (Instituto Mexicano del Seguro Social) (FIS/IMSS/PROT/G15/1412) and from the National Council for Science and Technology (Consejo Nacional de Ciencia y Tecnología) (CONACyT Salud 2015/CO1/261591).

\section{References}

[1] WHO International Consortium in Psychiatric Epidemiology, "Cross-national comparisons of the prevalences and correlates of mental disorders," Bull World Health Organ, vol. 78, pp. 413425,2000 .

[2] R. Kohn, I. Levav, J. M. Almeida et al., "Los trastornos mentales en América Latina y el Caribe: asunto prioritario para la salud pública," Revista Panamericana de Salud Pública/Pan American Journal of Public Health, vol. 18, no. 4-5, pp. 229-240, 2005.

[3] G. L. Hernández, O. G. Bermúdez, S. Spence et al., "Versión española de la Escala de Ansiedad para niños de Spence (SCAS)," Revista Latinoamericana de Psicología, vol. 42, pp. 1324, 2010.

[4] F. R. Schneier, J. Johnson, C. D. Hornig, M. R. Liebowitz, and M. M. Weissman, "Social Phobia: Comorbidity and Morbidity in an Epidemiologic Sample," Archives of General Psychiatry, vol. 49, no. 4, pp. 282-288, 1992.

[5] H. R. Wacker, R. Müllejans, K. H. Klein et al., "Identification of cases of anxiety disorders and affective disorders in the community according to ICD-10 and DSM-III-R by using the Composite International Diagnostic Interview (CIDE)," International Journal of Methods in Psychiatric Research, vol. 2, pp. 91-100, 1992.

[6] W. J. Magee, W. W. Eaton, H.-U. Wittchen, K. A. McGonagle, and R. C. Kessler, "Agoraphobia, simple phobia, and social phobia in the National Comorbidity Survey," Archives of General Psychiatry, vol. 53, no. 2, pp. 159-168, 1996.

[7] E. Weiller, J.-C. Bisserbe, P. Boyer, J.-P. Lepine, and Y. Lecrubier, "Social Phobia in General Health Care: An Unrecognised Undertreated Disabling Disorder," The British Journal of Psychiatry, vol. 168, pp. 169-174, 1996.

[8] R. C. Kessler, K. A. McGonagle, S. Zhao et al., "Lifetime and 12-month prevalence of DSM-III-R psychiatric disorders in the United States: results from the National Comorbidity Survey," Archives of General Psychiatry, vol. 51, no. 1, pp. 8-19, 1994.

[9] M. B. Stein, M. J. Chartier, A. L. Hazen et al., "Paroxetine in the treatment of generalized social phobia: Open-label treatment and double-blind placebo-controlled discontinuation," Journal of Clinical Psychopharmacology, vol. 16, no. 3, pp. 218-222, 1996.

[10] M. T. Bobes, M. Bascarán, and M. P. Bousoño, “Trastorno de ansiedad social: actualidad clínica y terapéutica," Salud Global, vol. 6, pp. 1-7, 2003.

[11] M. Martínez, Las Plantas Medicinales de México, vol. 1, Librería y Ediciones Botas, México, 1989. 
[12] E. Estrada, Jardín Botánico de Plantas Medicinales Maximino Martínez, Universidad Autónoma de Chapingo, Departamento de Fitotécnia, México, 1985.

[13] J. Tortoriello and X. Lozoya, "Effect of Galphimia glauca methanolic extract on neuropharmacological tests," Planta Medica, vol. 58, no. 3, pp. 234-236, 1992.

[14] R. A. Toscano, A. Ortega, and E. Maldonado, "Structure of Galphgimine B," Acta Crystallographica, vol. C49, pp. 774-776, 1993.

[15] J. Tortoriello, Efectos de la aplicación local de galphimina-B sobre la actividad eléctrica de las neuronas del área ventral tegmental de ratas, Tesis de Doctorado en Ciencias Biomédicas (Fisiología), Facultad de Medicina, Universidad Nacional Autónoma de México, 1998.

[16] B. Prieto-Gómez, J. Tortoriello, A. Vázquez-Alvarez, and C. Reyes-Vázquez, "Galphimine B modulates synaptic transmission on dopaminergic ventral tegmental area neurons," Planta Medica, vol. 69, no. 1, pp. 38-43, 2003.

[17] J. Tortoriello, A. Ortega, M. Herrera-Ruíz, J. Trujillo, and C. Reyes-Vázquez, "Galphimine-B modifies electrical activity of ventral tegmental area neurons in rats," Planta Medica, vol. 64, no. 4, pp. 309-313, 1998.

[18] A. Herrera-Arellano, E. Jiménez-Ferrer, A. Zamilpa, M. Morales-Valdéz, C. E. García-Valencia, and J. Tortoriello García, "Efficacy and tolerability of a standardized herbal product from Galphimia glauca on generalized anxiety disorder. A randomized double blind clinical trial controlled with lorazepam," Planta Medica, vol. 73, no. 8, pp. 713-717, 2007.

[19] J. R. Davidson, N. L. Potts, and E. A. Richichi, "The Brief Social Phobia Scale," Journal of Clinical Psychiatry, vol. 52, pp. 48-51, 1991.

[20] B. Gandek, J. E. Ware, N. K. Aaronson et al., "Cross-validation of item selection and scoring for the SF-12 Health Survey in nine countries: results from the IQOLA Project," Journal of Clinical Epidemiology, vol. 51, no. 11, pp. 1171-1178, 1998.

[21] D. A. Chavira, M. B. Stein, and V. L. Malcarne, "Scrutinizing the relationship between shyness and social phobia," Journal of Anxiety Disorders, vol. 16, no. 6, pp. 585-598, 2002.

[22] N. Brunello, J. A. Den Boer, L. L. Judd et al., "Social phobia: Diagnosis and epidemiology, neurobiology and pharmacology, comorbidity and treatment," Journal of Affective Disorders, vol. 60, no. 1, pp. 61-74, 2000.

[23] M. B. Stein, M. Fuetsch, N. Müller, M. Höfler, R. Lieb, and H.-U. Wittchen, "Social anxiety disorder and the risk of depression: A prospective community study of adolescents and young adults," Archives of General Psychiatry, vol. 58, no. 3, pp. 251-256, 2001.

[24] D. C. Beidel and S. M. Turner, Childhood Anxiety Disorders. A Guide to Research and Treatment, Routledge, New York, NY, USA, 2005.

[25] C. A. Essau, J. Conradt, and F. Petermann, "Frecuency and comorbidity of social phobia and social fears in adolescents," Behaviour Research and Therapy, vol. 37, no. 9, pp. 831-843, 1999.

[26] K. M. Connor, J. R. T. Davidson, H. Chung, R. Yang, and C. M. Clary, "Multidimensional effects of sertraline in social anxiety disorder," Depression and Anxiety, vol. 23, no. 1, pp. 6-10, 2006.

[27] M. A. Van Ameringen, R. M. Lane, J. R. Walker et al., "Sertraline treatment of generalized social phobia: a 20-week, double-blind, placebo-controlled study," The American Journal of Psychiatry, vol. 158, no. 2, pp. 275-281, 2001.

[28] S. K. Singh, G. E. Barreto, G. Aliev, and V. Echeverria, "Ginkgo biloba as an Alternative Medicine in the Treatment of Anxiety in Dementia and other Psychiatric Disorders," Current Drug Metabolism, vol. 18, no. 2, pp. 112-119, 2017.

[29] M. Herrera-Ruiz, M. González-Cortazar, E. Jiménez-Ferrer et al., "Anxiolytic effect of natural galphimines from Galphimia glauca and their derivatives," Journal of Natural Products, vol. 69, no. 1, pp. 59-61, 2006.

[30] R. A. Vargas, A. Zamilpa, F. A. Aguilar, M. Herrera-Ruiz, J. Tortoriello, and E. Jiménez-Ferrer, "Pharmacokinetic study in mice of galphimine-A, an anxiolytic compound from galphimia glauca," Molecules, vol. 19, no. 3, pp. 3120-3134, 2014.

[31] D. Avilés, M. L. Herrera, R. Roman et al., "Pharmacological interaction between Galphimine-A, a natural anxiolytic compound, and Gabaergic drugs," International Journal of Pharmacology, vol. 11, pp. 944-955, 2015.

[32] A. Herrera-Arellano, J. E. Jiménez-Ferrer, A. Zamilpa, G. García-Alonso, S. Herrera-Alvarez, and J. Tortoriello, "Therapeutic effectiveness of galphimia glauca vslorazepam in generalized anxiety disorder. A controlled 15-week clinical trial," Planta Medica, vol. 78, no. 14, pp. 1529-1535, 2012.

[33] J. Sarris, "Herbal medicines in the treatment of psychiatric disorders: 10-year updated review," Phytotherapy Research, vol. 32, no. 7, pp. 1147-1162, 2018. 


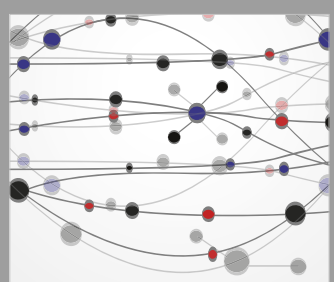

The Scientific World Journal
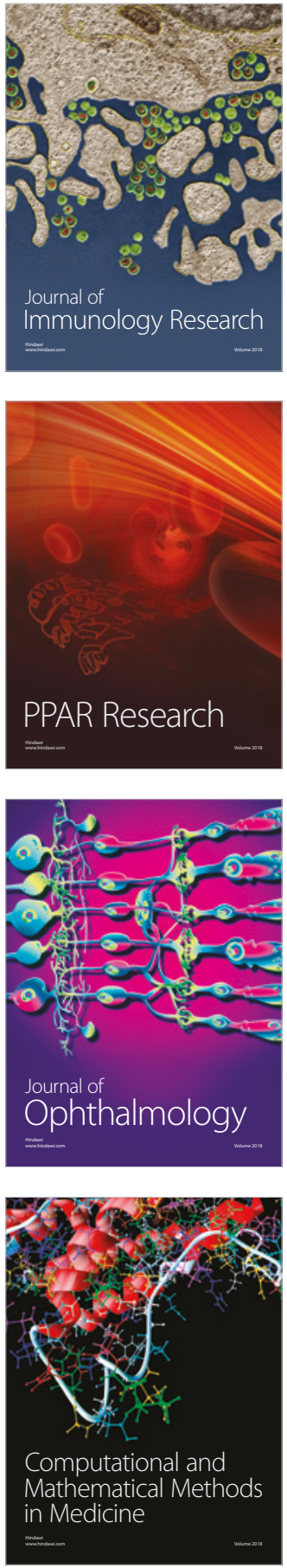

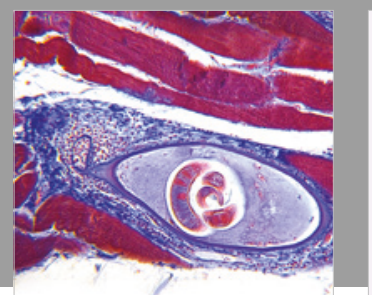

Gastroenterology Research and Practice

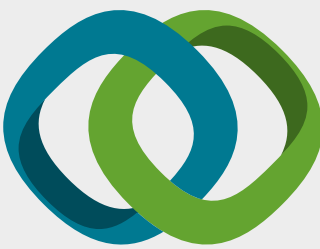

\section{Hindawi}

Submit your manuscripts at

www.hindawi.com
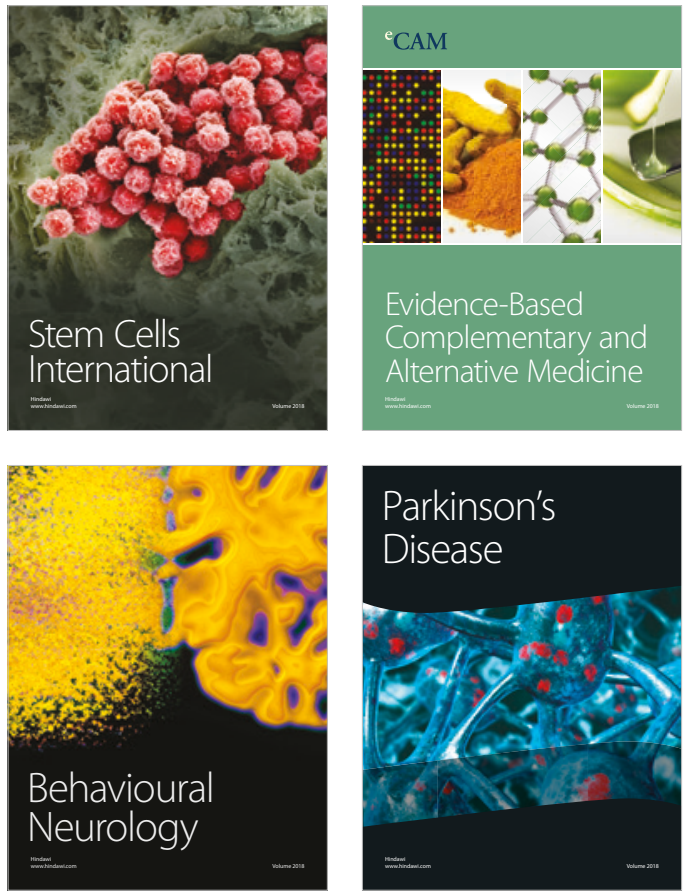

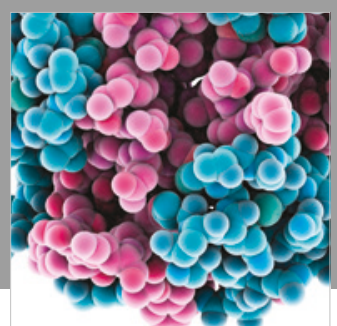

ournal of

Diabetes Research

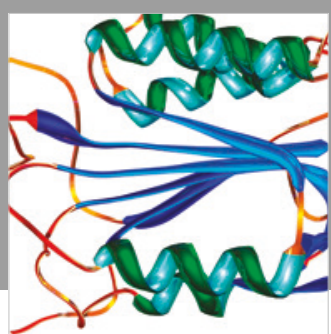

Disease Markers
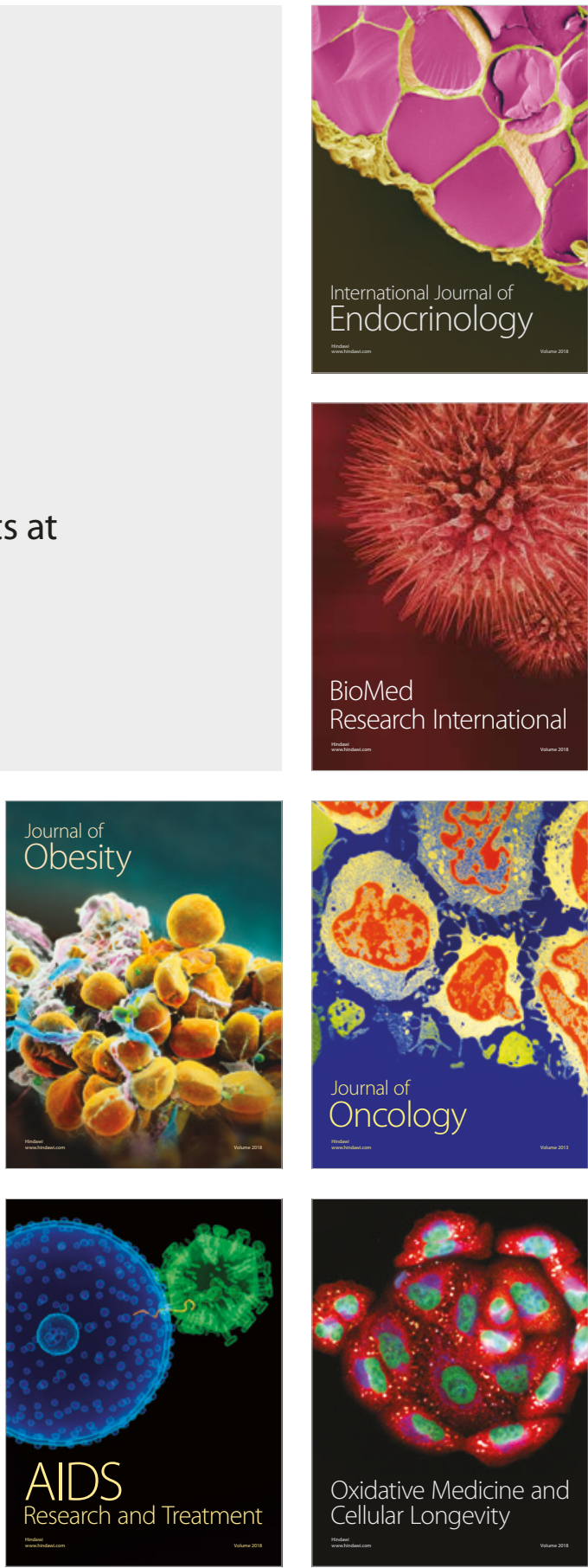